\title{
Photographing Fingerprints: Data Collection and State Surveillance
}

\author{
J onathan Finn1
}

\begin{abstract}
This paper examines fingerprint identification as a mode of state surveillance. Drawing on but critiquing the work of Simon Cole, it argues that the technique yielded a greater, more pervasive form of state surveillance by giving rise to new practices of data collection. This paper also highlights the photograph's role in fingerprint identification to argue for an essential transformation in law enforcement and surveillance practices announced by the intersection of fingerprinting and photography at the turn of the twentieth century. In contrast to traditional forms of visual surveillance, the collaboration of fingerprint identification and photography extended the surveillance gaze of the state in a manner often attributed to the rise of CCTV, enabling the state to bring all bodies - criminal and non-criminal alike - under surveillance. However, the unique capabilities afforded to the state through the intersection of fingerprint identification and photography remained largely theoretical until the advent of digital technologies in the 1960s and 1970s. At the start of the twenty-first century, advanced visual technologies and new media technologies reflect a restructuring of law enforcement and surveillance practices based on the aggregate collection of identification data. This paper argues that the continued photographing of fingerprints in contemporary law enforcement and state initiatives constitute heightened state surveillance and, as such, demands serious critical attention.
\end{abstract}

\section{Introduction}

Speaking at the 1926 International Association of Chiefs of Police convention, J. Edgar Hoover, then the newly appointed director of the Federal Bureau of Investigation, announced that the Identification Division had passed the million mark in its collection of fingerprint records (Dilworth 1977: 166). During the fiscal year 2001 the same agency received 15.4 million fingerprint submissions (Carey 2001). Most recently, and under the guise of a "war on terrorism" The United States Department of Homeland Security announced the United States Visitor and Immigrant Status Indicator Technology Program (US-VISIT), capturing digital images of the fngerprints and faces from the 35,000,000 non-citizens entering or leaving the country annually.

\footnotetext{
${ }^{1}$ Department of Communication Studies, Wilfrid Laurier University, Canada. mailto:jfinn@wlu.ca
} 
Hoover's comment in 1926 and the implementation of US-VISIT three-quarters of a century later attest to a continued effort by police in the United States to collect and archive personal identification data and to the central importance of fingerprinting in that effort. The tremendous economy of the fingerprint has assured the technique's prominence in law enforcement practices, which are dependant on the rapid collection, analysis and exchange of identification data. Yet despite its dominant position in law enforcement and identification practices, fingerprinting has received relatively little critical attention, Simon Cole's (1998a; 1998b; 2001) work being the notable exception. This lack of attention is of particular concern as digital technologies now enable law enforcement agencies to amass aggregates of identification data to an extent far beyond what was possible with traditional ink-based fingerprint systems.

This paper examines fingerprint identification as a mode of state surveillance. Simon Cole has shown how the technique's adoption into Western police practices worked in concert with broadening criminal laws to bring more criminal bodies under state surveillance. By casting a wider net, Cole stresses, more criminals were caught and more were brought under the watchful eye of the state through the compilation of greater numbers of criminal records. I agree that fingerprinting greatly assisted in this effort; however, I argue that the technique yielded a greater, more pervasive form of state surveillance by giving rise to new practices of data collection.

The collection, exchange and interpretation of fingerprint data operate through the manipulation and mediation of images. Fingerprinting is a highly visual and, I argue, largely a photographic process. This paper highlights the photograph's role in fingerprint identification to argue for an essential transformation in law enforcement and surveillance practices announced by the intersection of fingerprinting and photography at the turn of the twentieth century. I argue that, in contrast to traditional forms of visual surveillance that are based in direct observation and faceto-face interaction, the collaboration of fingerprint identification and photography extended the surveillance gaze of the state in a manner often attributed to the rise of CCTV (Norris 2003; McCahill 1998). The ability to photograph fingerprints enabled law enforcement agencies to collect, exchange and interpret identification data independent of the physical presence and knowledge of the body and largely free of the spatial and temporal constraints which had informed prior police practices.

Prior to the development of fingerprinting, law enforcement agencies used the camera to document known, criminal offenders. The camera's use by nineteenth century law enforcement agencies as a mechanism in the surveillance and control of growing urban populations has been well documented by scholars working in the history and theory of photography and visual culture (Tagg, 1988; Sekula 1986; Green 1984, 1985a, 1985b, Lalvani 1996; Gunning 1995). However, just as Cole stresses that fingerprinting brought more criminal bodies under state surveillance, work addressing the use of photography in law enforcement tends to emphasize the role of the camera to document criminal bodies. In contrast to this I stress that the collaboration of fingerprint identification and photography at the turn of the twentieth century enabled the state to bring all bodies - criminal and non-criminal alike - under surveillance.

The unique capabilities afforded to the state through the intersection of fingerprint identification and photography remained largely theoretical until the advent of digital technologies in the 1960s 
and 1970s. Now at the start of the twenty-first century, advanced visual technologies such as Automated Fingerprint Identification Systems foster the collection, storage and use of fingerprint data on a seemingly limitless number of bodies. Importantly, new media technologies and their use in programs such as US-VISIT do not merely enhance the communications capabilities of the state; rather, they reflect a restructuring of law enforcement and surveillance practices based on the aggregate collection of identification data. This paper argues that the continued photographing of fingerprints in contemporary law enforcement and state initiatives constitute heightened state surveillance and, as such, demands serious critical attention.

\section{Representing the Criminal: Rogue's Galleries and Bertillon Identification Cards}

To understand the unique features afforded to law enforcement through fingerprinting and its collaboration with photography it is necessary to briefly outline the use of the camera by police prior to fingerprinting. Photo-mechanical reproduction developed over a half-century from the experiments in the 1820s by Joseph Nicéphore Niépce and Jacques Louis Mandé Daguerre with the camera obscura to the 1888 release of the first Kodak camera, giving rise to what photographic historian and theorist John Tagg has called "the era of throwaway images" (1988: 56). From its inception, the camera's potential as a tool to document and monitor bodies was acknowledge and seized upon by social institutions, including hospitals, prisons, asylums, reformatories, schools and law enforcement agencies. The photograph's basis in chemical and mechanical processes gave significant weight to the scientific legitimacy and evidentiary status of the image. ${ }^{2}$ By 1841 the French police began to use daguerreotype cameras to document prisoners (Tuttle 1961: 4). In the United States, the San Francisco Police department began daguerreotyping prisoners in 1854, followed by departments in New York in 1858, Cleveland in the late 1860s and Chicago in 1870 (Cole 1998a: 51; Phillips 1997: 19; Tuttle 1961: 16). And in Canada, the Toronto Police collected photographs of criminals beginning in 1874 (Cooper 1981). The noted photographers Oscar G. Rejlander and W.B. Woodbury wrote on the topic in 1872 and 1875 editions of The British Journal Photographic Almanac respectively. By the last decades of the nineteenth century police departments in major metropolitan areas across the world were using the camera to document and monitor criminals.

Photographs of criminals were initially compiled into albums called rogue's galleries. These would typically house images and criminal history information on a few hundred individuals. The essential purpose of the rogue's gallery was to facilitate the surveillance and identification of criminal bodies by serving as a visual reference for police. As part of the visual vocabulary of police, the mug shot fulfilled two primary purposes; one, it aided in the surveillance of criminals while not in police custody; two, the archived photograph could be used as evidence of a criminal's identity if he or she were arrested at a later date and gave a false name to avoid

\footnotetext{
2 Lorraine Daston (1992) and Peter Galison (1998) suggest that mechanical objectivity also developed through the removal of the subjectivity of the scientist in the image. They refer to this as

"noninterventionist objectivity."
} 
increased penalties associated with recidivism. In each case the mug shot had one primary function: to document criminal identity.

As crime rates rose, the galleries grew in size, books were replaced by filing cabinets, and the expanding archives presented a central problem for police. Use of the galleries was dependent on an officer's ability to familiarize themselves with the faces, names and information compiled in the books and cabinets. Therefore, as the size of the galleries increased, their utility decreased. To exemplify the problem, Berlin's gallery grew to such an extent that, by 1877 , it was subdivided into ten crime-based groups and required three attendants. In 1880 the Berlin gallery housed 2135 images and within three years this had increased to 3459 (Tuttle 1961: 8).

A solution to the central problem of the rogue's gallery was developed by Alphonse Bertillon during his work with the Paris Prefecture of Police (Rhodes 1956). After taking a clerking job with the Paris Police in 1879, Bertillon identified that the problem plaguing the department's identification practices was the vast number of photographs in its collection. Due to the tremendous ease and speed with which photographs could be produced, the department had accumulated tremendous sums of images but lacked any real way to utilize them. In response to this problem Bertillon developed his anthropometric system of identification (Bertillon 1890; $1893 ; 1975)$.

Bertillon's system involved recording specific identification data onto a standardized form. Law enforcement officers would first record detailed anthropometric measurements of eleven body parts: height, head length, head breadth, arm span, sitting height, left middle finger length, left little finger length, left foot length, left forearm length, right ear length and cheek width. These measurements were supplemented with the physical description of the body, but particularly of the features of the face and head. For this task, Bertillon devised a short-hand language describing the minute details of the body in tremendous detail. The final aspect of Bertillon's identification system was the recording of one full face and one profile photograph. The resultant identification card, or portrait parlé, was a comprehensive data-sheet, detailing the criminal subject.

Bertillon's system of identification was officially accepted by the Paris police in 1883 . The technique was adopted by law enforcement agencies across Europe, Canada and the United States and remained in use into the 1920s. Bertillon's reduction of bodies into a standardized series of measurements allowed police to compile and effectively utilize greater numbers of records, ultimately bring more criminal bodies under state surveillance. Despite the significant impact Bertillon's work had on the communications and records-keeping capabilities of police, I stress that the use of the camera remained the same. Bertillon promoted the photograph as a supplement to the detailed anthropometric data, which he believed constituted the true measure of identity. Throughout its use by law enforcement agencies of the nineteenth and early twentieth century, the camera was used to document a body that was already known to be normal or deviant. Identification as criminal or normal preceded the use of the camera. Whether in rogue's galleries or Bertillon identification cards, the photograph served as a representation of a known criminal body. 
As noted at the start of this paper, the adoption of the camera by law enforcement agencies in the mid-nineteenth century through to the mobilization of the photograph in the work of Alphonse Bertillon has received a significant amount of critical attention in the work of photographic historians and theorists such as Tagg, Allan Sekula (1986), David Green (1984, 1985a, 1985b), Suren Lalvani (1996) and Tom Gunning (1995). This work has addressed the ways in which the camera was employed by the social institutions of Foucault's (1979) 'carceral network' in the surveillance and control of growing urban populations. This body of work is essential in understanding the social and historical development of photography as a documentary and evidentiary medium as well as its deployment in broad, discursive networks as mode of surveillance and social control. Nonetheless, this work leaves space for continuing critical investigation. The myriad of new visual and information technologies at work in criminal identification calls for a rethinking of this material, which refers almost exclusively to nineteenthcentury practices. Similarly, in its focus on the use of the image in rogue's galleries and Bertillon identification cards, this work takes as its subject of study, photographic representations of known, identified bodies. This paper, and the larger project from which it is derived, begins where this work ends, at the turn of the twentieth century and the transformation in law enforcement practices from Bertillon's anthropometry to fingerprinting. Fingerprinting transformed the role of the photograph within law enforcement practices through an essential inversion: in fingerprinting the use of the camera precedes identification.

\section{Photographing Fingerprints}

Fingerprint identification developed contemporaneous to Bertillon's work in Paris. The rich and diverse history of fingerprinting has been addressed in significant depth, most thoroughly by Simon Cole (1998a, 1998b, 2001; Cherrill 1954; Duncan 1942; Finn 2003; Allison 1973; Wentworth 1932; Wilton 1938). Rather than recount that history here, I highlight some of the central features within the history of fingerprinting in order to foreground discussion of the unique collaboration of photography and fingerprint identification.

The origins of fingerprinting are commonly traced to the work of Dr. Henry Faulds and Sir William Herschel. In the late 1870s Faulds, then a physician at Tsukiji Hospital in Japan, was asked to examine finger impressions left in ancient Japanese pottery. This project inspired him to collect and study the prints of humans from various nationalities with hopes of finding racial or familial similarities. In an 1880 article in Nature, "On the Skin-furrows of the Hand," Faulds notes that his attempts to trace heredity through the examination of fingerprints were inconclusive but that fingerprinting presented several other potential uses. Chief among these was the ability to identify criminals. Faulds writes: "When bloody finger-marks or impressions on clay, glass, \&c., exist, they may lead to the scientific identification of criminals" (1880: 605). He then refers to two cases in which he was able to use fingerprinting successfully to aid in criminal investigations and concludes "there can be no doubt as to the advantage of having, besides their photographs, a nature-copy of the for-ever-unchangeable finger-forms of important criminals" (1880: 605). 
William Herschel, an employee for the British East India Company, made a subsequent contribution to Nature: "Skin Furrows of the Hand" (1880). Herschel's work on fingerprints began in the 1850s when he was working in Bengal and used fingerprints in place of written signatures on contracts. Like Faulds, Herschel tried to trace heredity through fingerprints and was also unsuccessful. He writes:

My inspection of several thousands has not led me to think that it will ever be practically safe to say of any single person's signature [fingerprint] that it is a woman's or a Hindoo's, or not a male European's.... In single families I find myself the widest varieties (1880: 76).

Like Faulds, Herschel saw the potential for fingerprints to be used in criminal justice practices, proposing that prisoners entering jail be fingerprinted for potential identification needs. Despite their differences or the order in which their work appeared, Faulds, Herschel, and other early investigators approached fingerprints similarly in that they investigated them as unique identifiers. The central concern of this work was to prove that no two fingerprints could ever be the same.

As described by Faulds and Herschel, the fingerprint was prone to the problems facing other modes of identification. As an inscription of the body, as a piece of data, the fingerprint's value lay in its potential to function in a larger system of criminal identification. The fingerprint had to be organized and classified. Contemporaries of Faulds and Herschel sought ways to mobilize the fingerprint and transform it into the basis for a complete system of identification. The work of Francis Galton and Dr. Juan Vucetich was of significant importance in this regard. Galton took up Faulds' work through the prompting of his cousin, Charles Darwin, ultimately seeking evidence of heredity through the examination of fingerprints. A necessary corollary to his scientific investigations was the construction of a system for ordering and classifying his data. Although unsuccessful in his quest to prove heredity through fingerprints, Galton did produce essays and a detailed text on the topic in which he described a system to classify prints (1888a; 1888b; 1892). A year prior to Galton's 1892 text Dr. Juan Vucetich established the Identification Bureau in Argentina and developed a system for classifying fingerprints into a large, workable file. Vucetich's system was employed throughout Latin America. Simon Cole calls Vucetich's "the first classification system which rendered finger prints a practical means of indexing a large criminal identification file" (1998a: 230).

The work of Sir Edward Henry and his assistant, Azizul Haque, announced an essential transformation in fingerprint identification. Like Herschel, Henry worked under colonialist governments in India. Henry devoted specific attention to creating a detailed system for collecting, sorting and searching fingerprints. He divided fingerprints into four basic types: arches, loops, whorls, and composites. These types were further subdivided according to distinction in the ridge characteristics of the print. Using these categories, Henry devised a complete classificatory scheme. His 1900 text, Classification and Uses of Finger Prints, quickly became the central text on the topic. The resultant 'Henry system' remains at the foundation of current fingerprinting practices. 
From its outset, fingerprinting appeared to avert the problems that plagued Bertillon's system of identification. Fingerprints provided the necessary information (for identification) in a more condensed physical space. Further, in contrast to the complexity of Bertillon's photographic, textual and numerical identification cards, fingerprints offered a single, visual statement. In addition, fingerprints afforded a more direct representation of the biological body than did photographic portraits or anthropometric measurements. More than just a visual, numeric or textual representation, they presented a literal, physical trace of the body. Writing an early history of the technique, George W. Wilton highlights this biologically based authority: "But, while photographic prints or slides and recorded voices are artificial, the evidence of fingerimpressions is the natural inference of presence at some particular spot of the maker" (1938).

Developments in communication technologies such as the fax, first demonstrated in 1902 (Coopersmith 1993; Costigan 1978), and the ability to transmit photographs over radio, described in 1920 (Lescarboura 1920) connected law enforcement practices across the Atlantic Ocean. The tremendous economy of the fingerprint and its acceptance as the index of the body, as the "natural inference of presence" of the individual, assured the technique's prominence within law enforcement practices that were increasingly reliant on communication. Centralized federal level fingerprint archives took form in the establishment of the Canadian Criminal Identification Bureau in 1911 and the Identification Division of the Federal Bureau of Investigation in 1924. Only two years after its inception, J. Edgar Hoover, then the newly appointed director of the Federal Bureau of Investigation, boasted to the law enforcement community that the Identification Division had passed the million mark in its collection of fingerprint records (Dilworth 1977: 166). By the 1930s fingerprinting fully supplanted Bertillonage as the primary system of identification within the Western world and the technique had gained full acceptance as being scientifically and legally valid. ${ }^{3}$

Understood in this context, fingerprinting merely extended existing capabilities of police. Fingerprinting enabled police to amass greater numbers of records on criminals and to bring greater numbers of bodies under surveillance. As Cole notes the technique was used in conjunction with increasingly broad criminal laws, "to bring the poor, the ill, the addicted into the custody of the state under the guise of petty crimes, such as prostitution, vagrancy or intoxication" (1998a: 276). However, where Cole emphasizes increased state surveillance through the arrest of greater numbers of criminal bodies, I stress that the specific collaboration of the theory of fingerprint identification and photography announced law enforcement practices based on the collection, storage and interpretation of identification data of criminal, non-criminal and unidentified bodies alike.

Like Bertillon's anthropometry before it, fingerprinting yielded data derived directly from the physical body. Persons apprehended and brought to the police station would have their fingerprints taken. In this sense, prints were collected directly from the bodies of known criminals. However, unlike earlier forms of identification, fingerprinting enabled the collection and use of a new type of data: that derived indirectly from the body, lifted from the live

\footnotetext{
${ }^{3}$ Colin Beavan (2001) and Simon Cole (1998b) discuss the founding court cases in Britain and the United States respectively.
} 
environment. This is the essential difference between fingerprinting and earlier forms of identification. Fingerprints can be collected independent of the presence and knowledge of the body to which they attest and independent of traditional spatial and temporal constraints.

The camera's role in this new system of identification was paramount. Using a camera, officers could collect fingerprints long after the body had disappeared. The procedure of this new method of identification and its promise were described by Superintendent Arthur Hare at the 1904 International Association of Chiefs of Police convention. He notes:

In cases of murder, the marks left by the blood stained fingers have been photographed and compared with the finger prints of the habitual criminal on file in the bureau, and by reason of the simple classification, is sometimes identified and the crime brought home to an individual who would never have been suspected but for the clue which nature has provided (Dilworth 1977: 60).

Superintendent Hare's comment references the mobilization of the camera to link the direct and indirect presence of the individual. The individual's presence at the crime scene, via the "blood stained fingers," is tied to his presence in the bureau's file by the deployment of the photograph. The individual body exists in both locations independently and is only made known and identified as criminal through the use of the camera.

The unique opportunities afforded through the intersection of fingerprint identification and photography are perhaps best exemplified in a technique proposed by F.H. DePue of the San Francisco Police Department at the 1902 International Association of Chiefs of Police convention. DePue's system worked by comparing photographic projections of suspected and wanted persons. The enlarged, projected images were dissected into a grid and anthropometric measurements were taken from the images. DePue's system was unique in the way he promoted the use of the camera. He explains:

By the DePue system you can take a flash photo anywhere of your suspected party, do your own measuring at your own sweet pleasure in the secrecy of your office, without your subject having the slightest knowledge of what is going on (Dilworth 1977: 50).

DePue's system highlights the unique features of fingerprint identification and its collaboration with photography. First, the camera enabled the collection of information on individuals in a subtle and non-physical way. Second, the resultant images could be examined and re-examined infinitely and independent of the physical body. Finally, this entire process could be performed without the individual's knowledge.

I am not suggesting that the ability to photograph fingerprints announced a sudden and complete shift in law enforcement practices where police randomly collected fingerprints in the hopes of finding criminals. Early uses of the technique mirrored prior identification practices in that data was collected directly from the bodies of known offenders. However, fingerprinting did give rise 
to new police practices and a new mode of state surveillance based on the aggregate collection of identification data.

I want to stress two primary and interrelated ramifications of the shift in law enforcement and identification practices announced by fingerprinting. First, photography and fingerprint identification enabled the collection of aggregates of data on known and unknown bodies alike. Prints collected from the live environment were done so with the potential of identification, not because they served to represent a known, criminal body. This expanded the scope of law enforcement from the individual, criminal body to a larger, abstract social body. Second, photography and fingerprint identification mobilized law enforcement agencies, extending their capabilities and reach and creating a new, more pervasive form of state surveillance. The latency of fingerprints and the mobility of the camera meant, at least theoretically, that all public and private space could be subject to police surveillance (in the form of data collection) and that all bodies, manifest in their fingerprints, were potentially criminal.

The unique possibilities announced by the collaboration of fingerprint identification and photography remained largely theoretical until the development of digital technologies in the 1960s and 1970s. During these two decades companies including McDonnell Douglas Corporation, KMS Technology Center, Sperry Rand, Rockwell International and NEC began to experiment with recording fingerprints electronically. ${ }^{4}$ Law enforcement agencies adopted the technology quickly. Among the first to employ automatic fingerprint identification equipment were the New York State Identification and Intelligence System in 1968, the Atlanta Police Department in the early 1970s, the Kansas City Police Department in 1974 and the Nassau County Police Department in 1975 (Reed 1981: 320-321). At the federal level, the FBI installed its first fingerprint scanner and began digitizing its extensive fingerprint collection in 1972 (Cole 2001: 252). A year later the Royal Canadian Mounted Police installed its automated system (Reed 1981: 323). By the late 1970s and early 1980s Rockwell International and NEC had developed complete electronic fingerprinting units for commercial sale (Cole 2001: 253). These units, referred to as Automated Fingerprint Identification Systems (AFIS) were capable of scanning, classifying, filing, storing and searching fingerprints electronically and are now the mainstay of law enforcement agencies. More recently, "live-scan" systems such as that illustrated in Figure 1 (overleaf) enable officers to capture and archive electronic images of an individual's fingerprints, palm prints and face. When the individual is not in custody and therefore the "live-scan" system cannot be used, digital cameras enable officers in the field to collect vast amounts of identification data. Fingerprints can be entered directly into law enforcement databases from the field, or they can be "lifted" (a copy is taken by applying adhesive tape or another material to a dusted print and "lifting" it off of a surface) and brought back to the police station to be scanned and archived using peripheral devices like that in Figure 2 (overleaf). The majority of law enforcement agencies in the United States and Canada currently use a combination of the traditional, ink-based system and the new, paperless and inkless live-scan systems. Despite these technological advances the basic classificatory and

\footnotetext{
4 On the development of Automated Fingerprint Identification Systems see: Brotman 1991; Cole 2001 (Chapter 10: Digital Digits); FBI 1999; Reed 1981; Wilson 1986.
} 
searching mechanisms remain remarkably similar to those developed at the turn of the nineteenth and twentieth centuries.

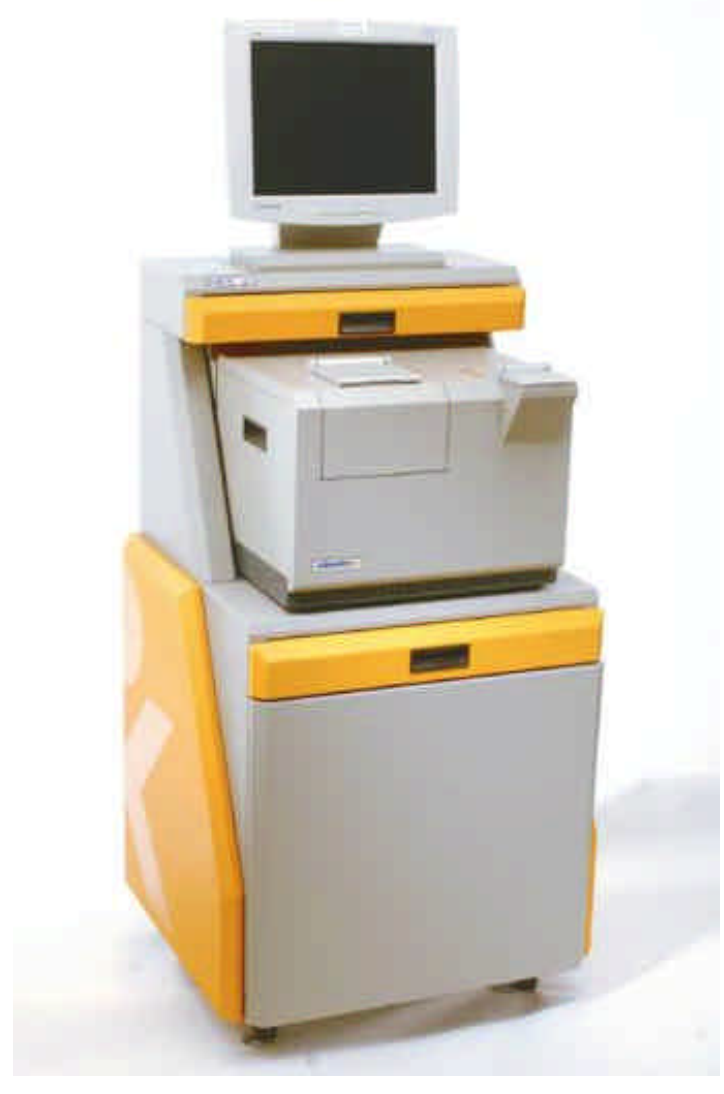

Figure 1 (left): NEC's LS21 ${ }^{\text {TM }}$ Live Scan Workstation. Law enforcement agencies can capture, archive, search and exchange fingerprints, palm prints and mugshots from this workstation.

(Photo courtesy of Sylvia Welch, Manager, Marketing and Communic ations, NEC Solutions (America) Inc.)

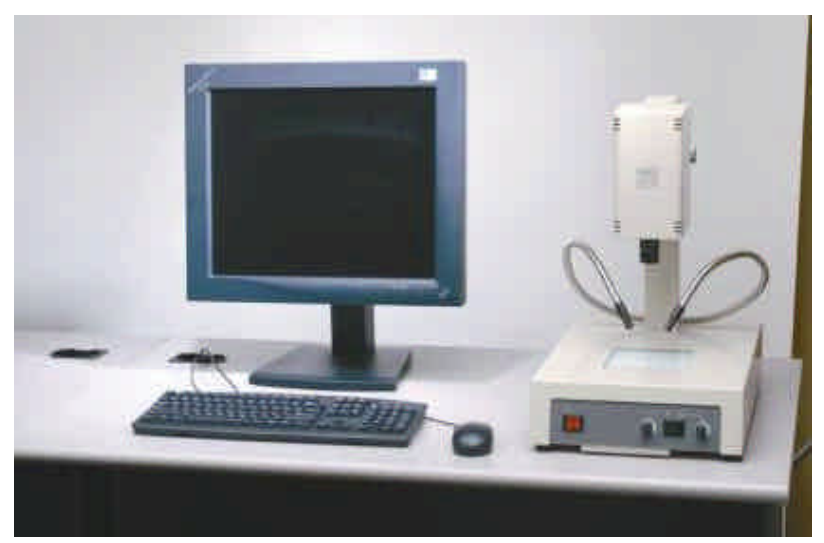

Figure 2 (above): A latent fingerprint workstation by NEC. Allows law enforcement personnel to scan latent prints for examination and archive and exchange prints within an AFIS program.

(Photo courtesy of Sylvia Welch, Manager, Ma rketing and Communic ations, NEC Solutions (America) Inc.)

The collection of identification data by law enforcement agencies in the nineteenth and most of the twentieth centuries remained limited by the material constraints associated with collecting, filing, searching and exchanging paper records. These material constraints are disappearing as law enforcement agencies move towards a paperless environment. The diverse implications and ramifications of this shift from analog to digital systems demand serious critical attention at both the theoretical and practical level. Here it is sufficient to note that new media technologies have removed many of the material constraints which helped shape law enforcement and identification practices for the past century and a half. The theoretical capabilities announced by the collaboration of fingerprint identification and photography have become a reality in the twentyfirst century. New media technologies have shifted the focus in law enforcement and related states practices from the individual criminal body to an aggregate social body. Rather than elaborate on this process in the abstract, I turn to turn to a concrete examination of a case of fingerprint identification. 


\section{Photographing Fingerprints from the Crime Sc ene to the Courtroom}

The camera's role in fingerprint identification has remained relatively constant throughout the history of the technique. Fingerprinting manuals from the early 1900s to the present describe a similar process. The camera is used initially to document the crime scene prior to investigation. Officers enter the scene, search for fingerprints and dust, illuminate or otherwise prepare prints to be photographed. Photographic enlargements are made from the collected prints away from the crime scene. Prints are classified according to the existing system, from the ten-print Henry system of the early 1900s to more current automated digital systems, and searched against a fingerprint file. Once a match is made photographic enlargements of the found and known prints are produced. The identifying features of the prints are marked on their photographs and described in an accompanying text.

To better understand the role of photography in fingerprint identification I turn to a fictional crime scene produced during an apprenticeship with the Forensics Identification Services Division of the Metropolitan Toronto Police..$^{5}$ The case is real in application and procedure but fictional in its goal. The purpose of the fictional scene was to trace the use of photographic representation in fingerprint identification from the collection of crime scene materials through investigation and into its use in the courtroom.

The fictional scene proceeds as follows: Scenes of Crime and Identification Officers examine and photograph a crime scene, its contents and its setting. ${ }^{6}$ Within the scene, sites that might reveal fingerprints (window sills, doors, glasses etc.) are dusted, illuminated through ultra-violet or infrared light, or manipulated in another way to make the prints visible? These prints are then either photographed, lifted, or both depending on the nature of the print. In this specific case, a dinner plate located at the crime scene is examined and dusted and fingerprints are found. All prints from the scene that can be lifted or photographed are taken to the police department where they are scanned into the Automatic Fingerprint Identification System. Using a computer mouse, an officer marks the idiosyncratic features of each print, their "ridge characteristics," and searches the database for similar markings (Figure 3 - overleaf). AFIS presents a series of possible matches, each of which is compared against the found prints. If a match is not made the print under examination remains in the database as a potential source for future investigations. If a match is made, the fingerprint and any accompanying information will be collected by the

\footnotetext{
5 As part of the MA degree in Art History at York University, Toronto I established an apprenticeship with the Forensics Identification Services Division of the Metropolitan Toronto Police. The apprenticeship took place during August of 1996. Throughout the month I worked with Scenes of Crime and Identification Officers to examine the use of photography within practices of criminal identification. Much of the information on fingerprinting was taken from this apprenticeship. This included access to various manuals and publications used in the training of Officers. Chief among the materials was the Ontario Police College's Scenes of Crime Manual and the following articles produced by the Metropolitan Toronto Police Identification Bureau: "History of Fingerprints;" "History of Identification by Fingerprints;" "Fingerprints as a Means of Identification;" "A Capsule Chronological History of Fingerprint Identification;" and "Structure of the Skin."

${ }^{6}$ Within the Metropolitan Toronto Police, Scenes of Crime Officers receive general training on evidence collection, including basic notes on photography. Identification Officers receive more specialized training, particularly in reference to the collection and photographing of crime scene materials.

${ }^{7}$ It is important to note that the collection of fingerprints is only one part of the larger investigative process. Other forms of potential evidence, such as objects at the scene are also collected and are photographed.
} 
examining officer. In our case a print from the dinner plate draws a match to a print in the database and both are prepared for further examination.

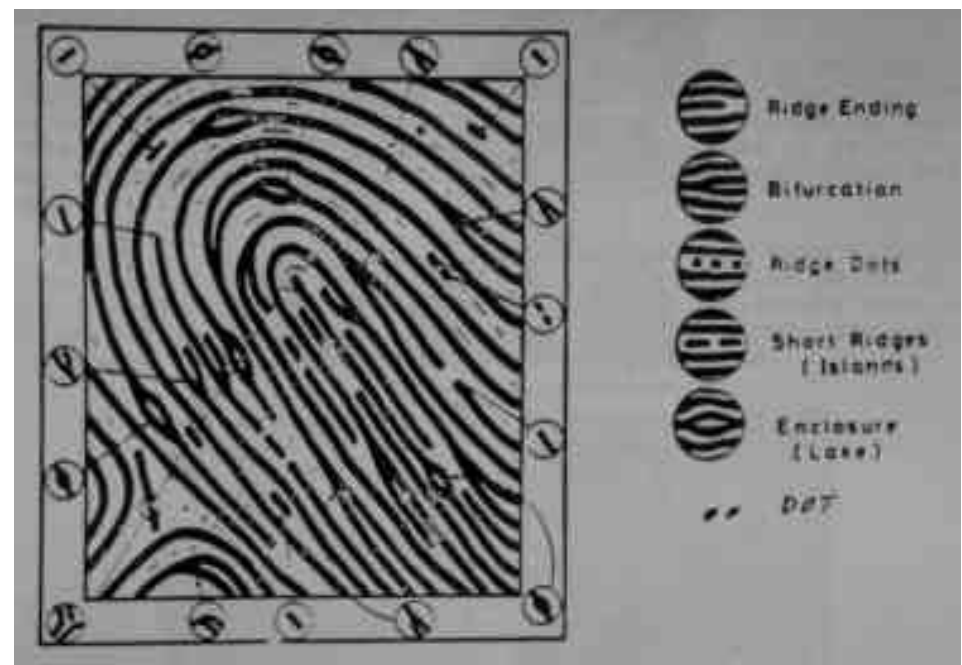

Figure 3: The ridge characteristics of the fingerprint. (Photo property of the author)

Identification by fingerprint takes place through matching the idiosyncratic features of found (from the crime scene) and known (on file with the police) prints. The first step is to locate the hand and finger from which the print originated (i.e. the left or right hand and the middle, index, etc. finger). Next the print's general pattern is noted (whether it swirls or moves in a given direction). The most significant part of the process is the identification of the ridge characteristics, sometimes still referred to as the "Henry details" or the "Galton details." The various combinations of these features, as dots, lakes, bifurcations and ridge endings are unique to each print. Using the ridge characteristics as signposts, the examining officer constructs a narrative that links the known and found print.

Although simplified, the scene described is representative of the general investigative procedure. The fictional scene demonstrates the central role of photography throughout the identification process. A first photograph is taken that positions the dinner plate within the context of the crime scene (Figure 4 overleaf). The second photograph locates the fingerprint on the plate (Figure 5 overleaf). The third is a close-up of the print (Figure 6, p.34). Once this general continuity is established the print is lifted onto acetate, enabling it to be scanned into AFIS and to be used for further investigation (Figure 7, p.34). In our fictional scene, AFIS produced a match to a latent print on file. The matching criminal record is obtained and an examination takes place (Figure 8, p.35).

For the examination the Identification Officer uses the third photograph from the series, which was the close-up image of the print. Both the close-up and the latent print (from the fingerprint chart) are re-photographed and enlarged to 8/12 by 11 inches (Figures 9 and 10,p.36). These two photographs are then read by the examining officer and prepared for use in court. The resultant fingerprint chart is accompanied by a narrative account of how the evidence is to be 
read (Figure 11, p.37). This material is combined with a detailed list of the examining officer's credentials and presented as final evidence.

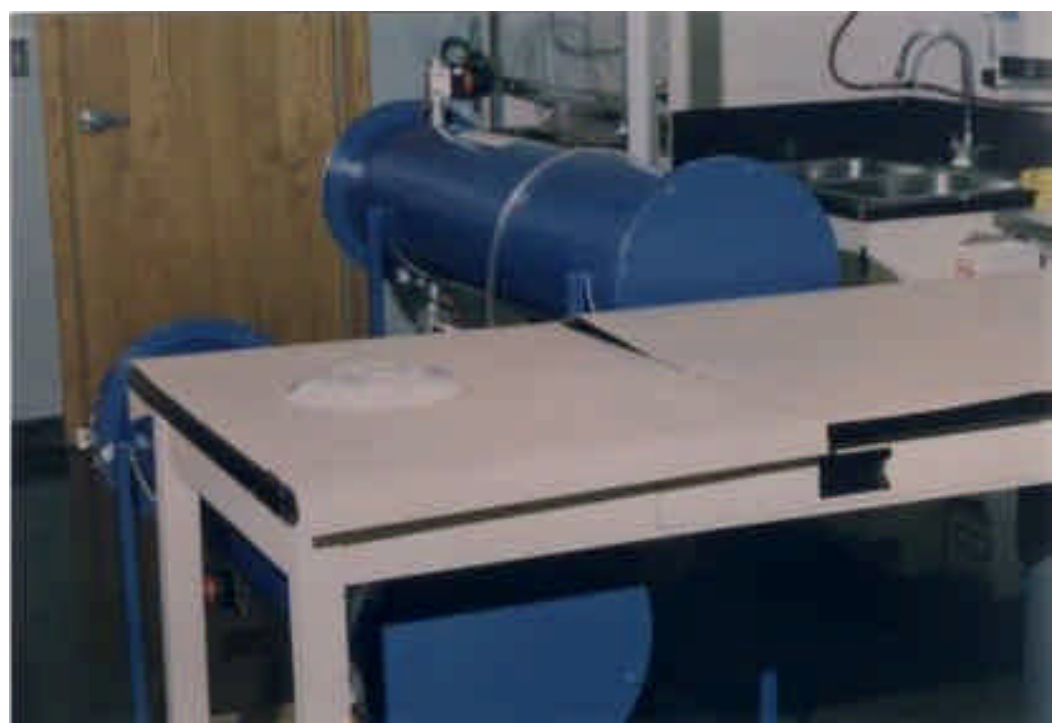

Figure 4: The first photograph positions the dinner plate within the context of the crime scene.

(Photo property of the author)

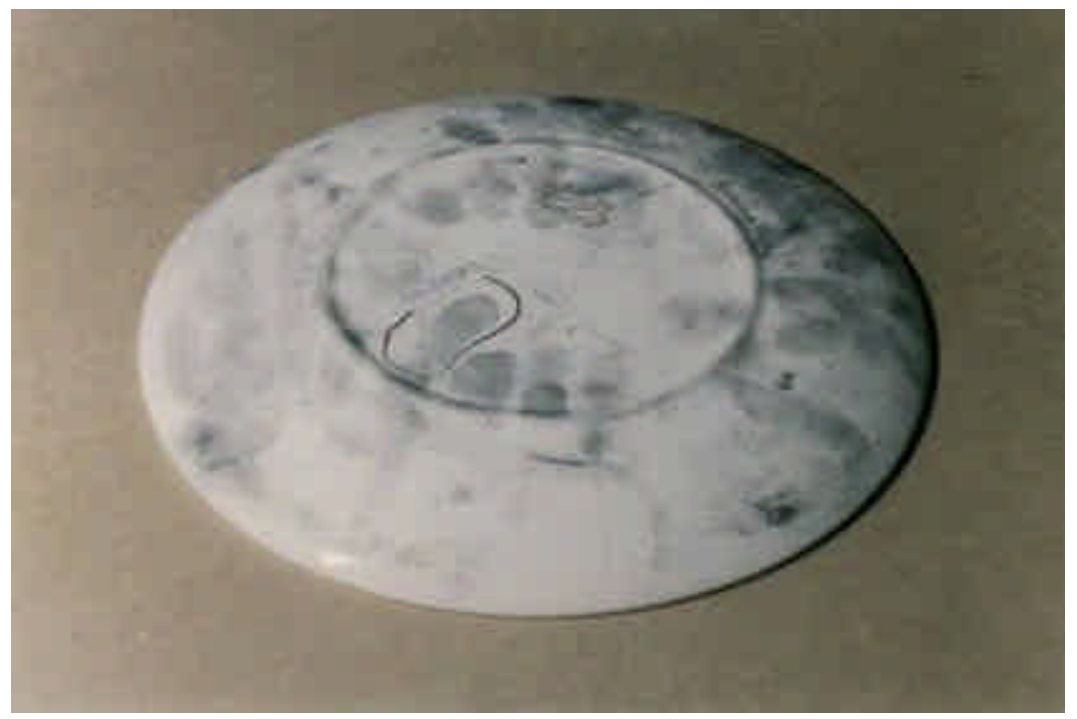

Figure 5: The second photograph positions the fingerprint on the dinner plate.

(Photo property of the author) 


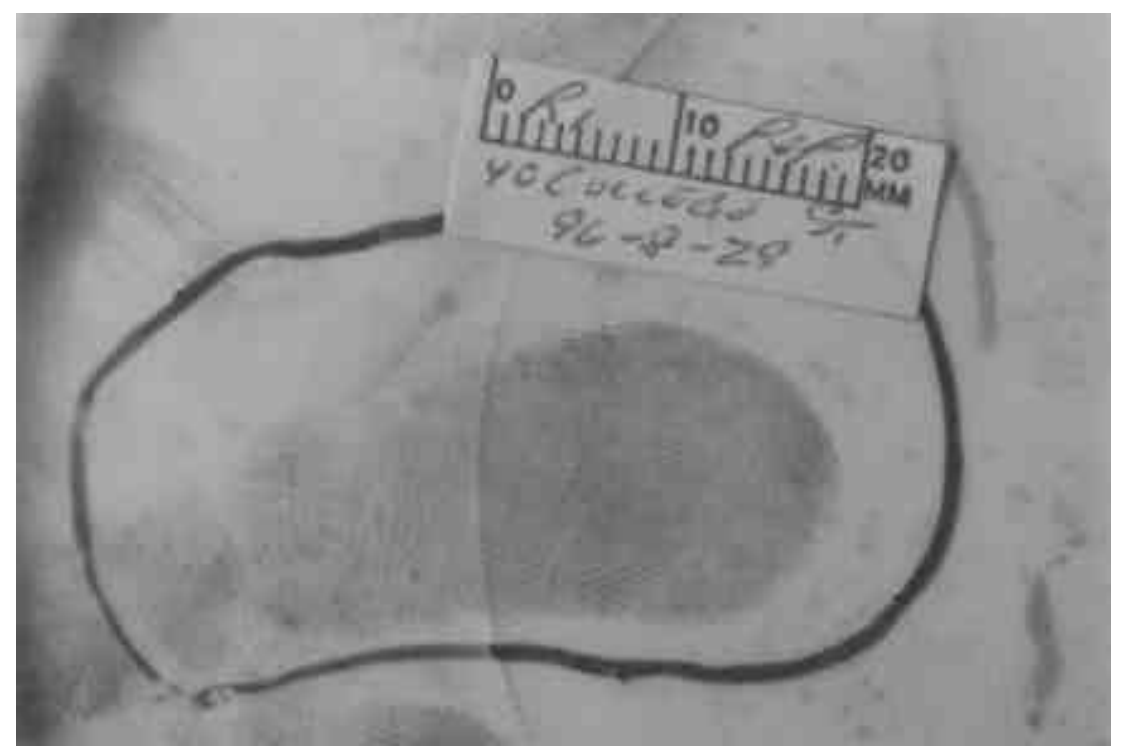

Figure 6: The third photograph isolates the found fingerprint. (Photo property of the author)

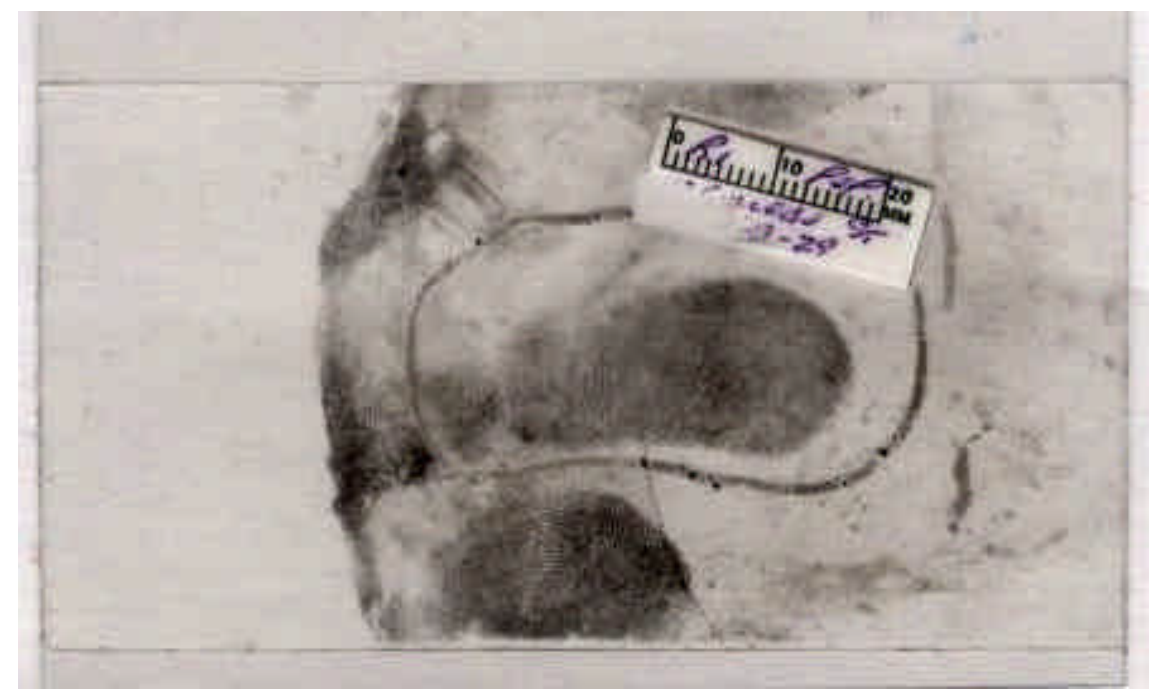

Figure 7: The print from the plate is lifted onto a sheet of acetate, enabling it to be scanned into the AFIS database.

(Photo property of the author) 


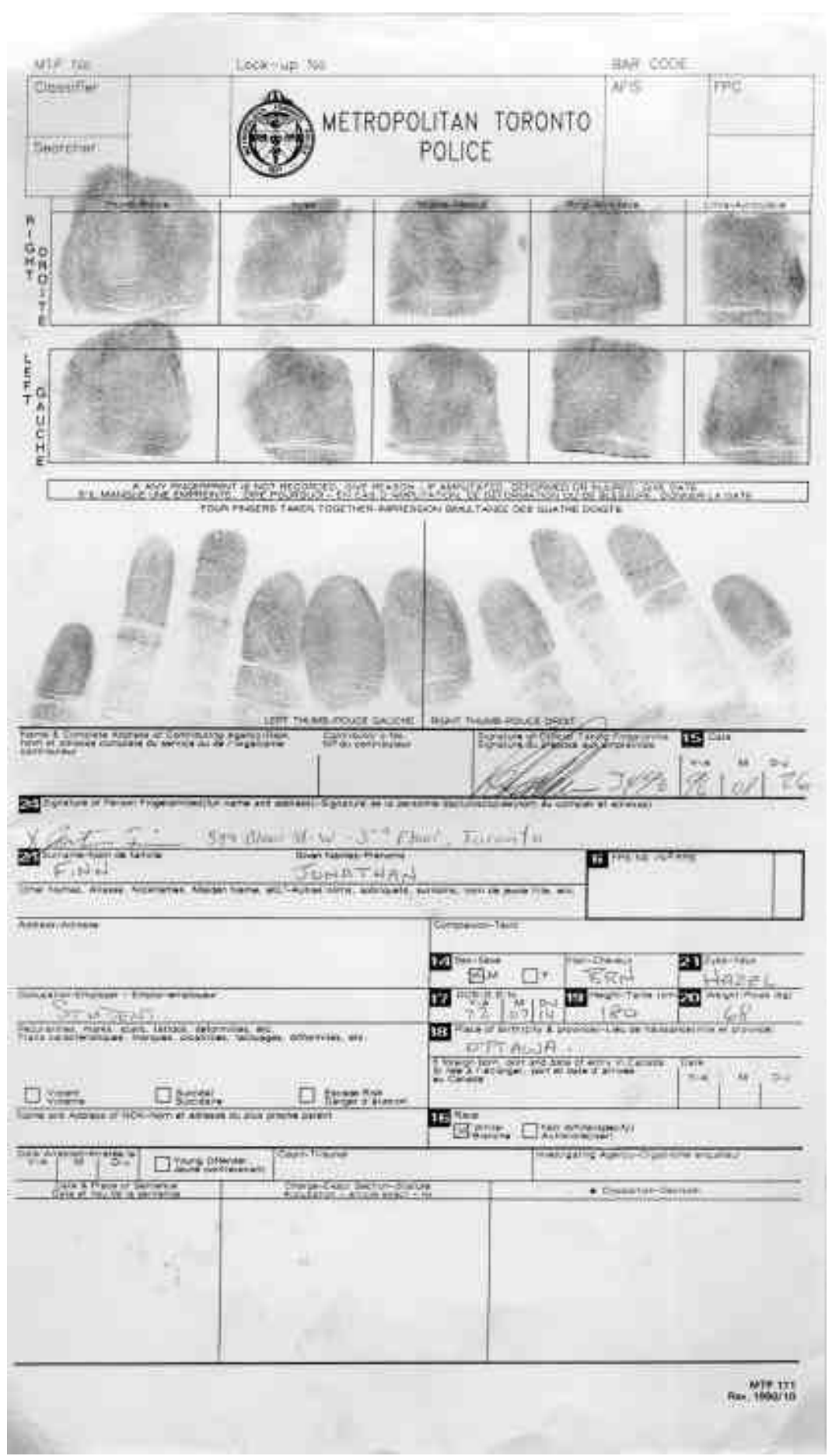

Figure 8: The criminal record matching the identified print is collected. (Photo property of the author) 
Finn: Photographing Fingerprints

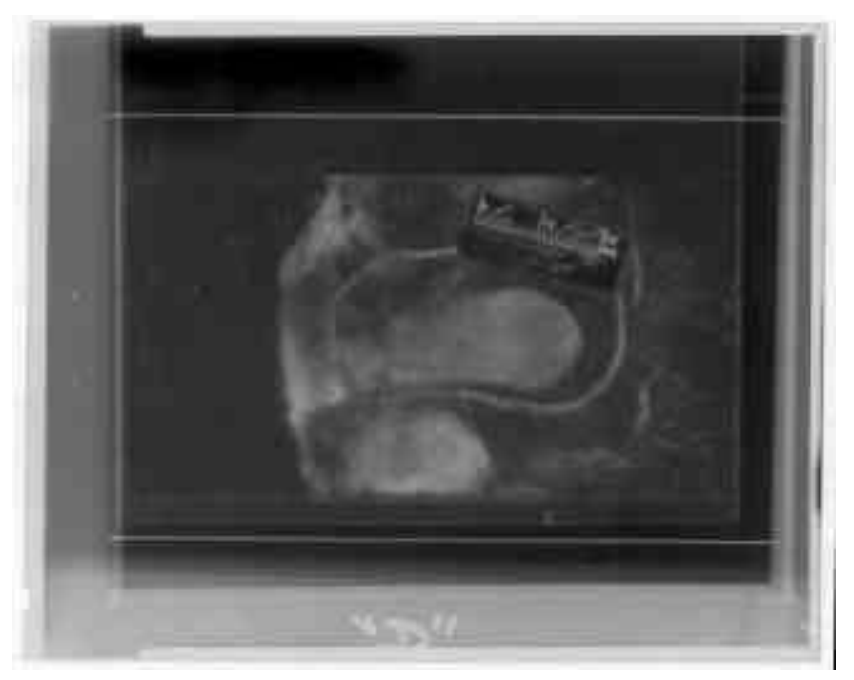

Figure 9: A negative is made from the found print to be enlarged for final identification and presentation in the fingerprint chart.

(Photo property of the author)

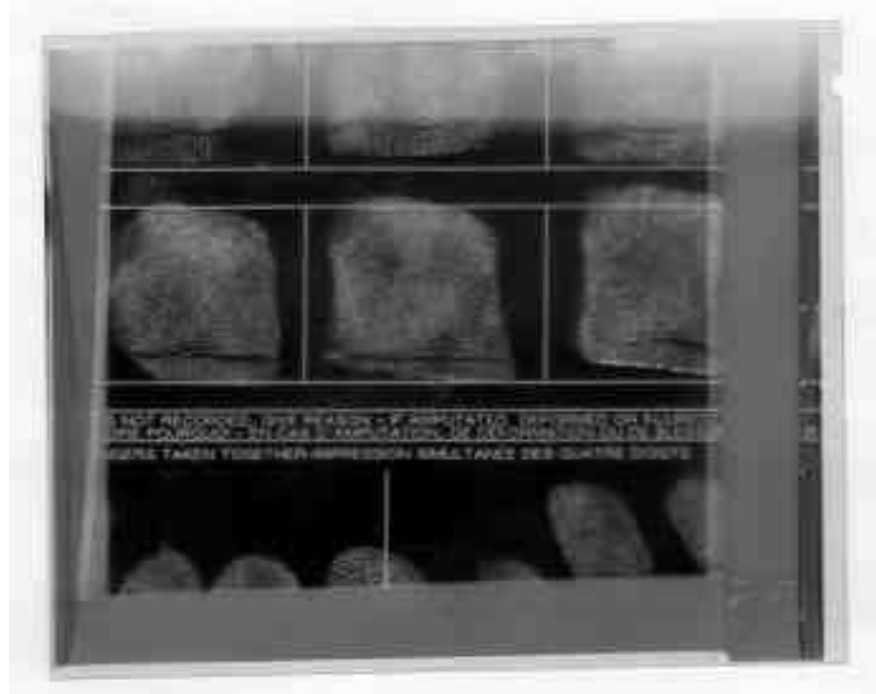

Figure 10: A negative is made of the latent print from the fingerprint record to be enlarged for final identific ation and presentation in the fingerprint chart. (Photo property of the author) 

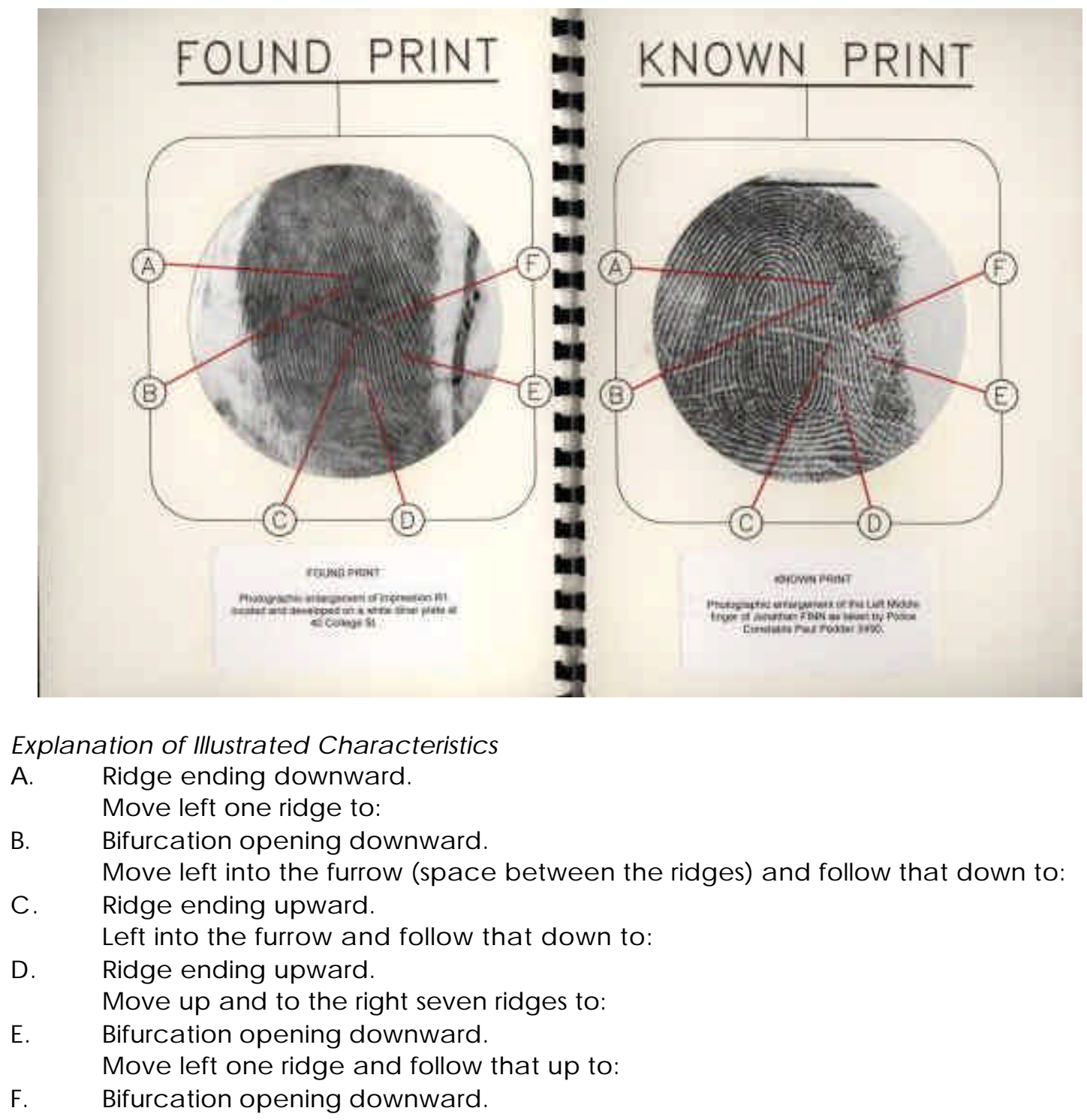

Figure 11: The fingerprint c hart with its accompanying na rative (Photo property of the author)

As the fictional scene demonstrates, the camera is the essential tool for the collection and interpretation of data used in the production of identification. The photographs establish a continuity of presence; a photographic paper trail linking the individual to the crime scene. The mechanically objective camera reproduces, represents and guarantees the "natural inference of presence" of the individual body from the crime scene to the courtroom. His presence on the dinner plate is tied to his presence in the Department's file and his identification as criminal takes place through the production and interpretation of photographs.

The unique features afforded law enforcement agencies by the ability to photograph fingerprints is exemplified in Figures 4, 5, 6 and 7. These images are not representations of criminal bodies 
as the images in rogue's galleries or Bertillon identification cards are; rather, they are representations of data. The fingerprints recorded in the photographs attest to bodies that are only potentially criminal, their identity to be determined through the process of interpretation. The unidentified, raw data in these images is transformed into a representation of a criminal or non-criminal body through the disciplinary framework of forensic science. The body identified in the final evidentiary statement, shown in Figure 11, as a criminal is not known to police at the time of data collection. The fingerprint is collected (photographed) and identified independent of the physical presence and knowledge of its maker and largely independent of traditional spatial and temporal constraints.

For purposes of clarity, the fictional scene traced the identification of a single fingerprint found at the crime scene. Crucially, numerous prints would be collected and photographed from any given crime scene. For example, had the fictional scene taken place in a restaurant any surface yielding fingerprints (plates, cutlery, glasses etc.) would be tested for prints. This process yields aggregates of fingerprints, which are then stored in AFIS databases. An individual present at the fictional crime scene, although not ultimately identified or arrested in relation to that case, could be linked to the fictional scene if fingerprinted at a later date either through arrest or other purposes including a background check for employment. The aggregates of fingerprints photographed from the scene remain archived as sites of latent or potential identification.

The data collection capabilities of police announced by the collaboration of fingerprint identification and photography, and as exemplified in the fictional crime scene, have increased exponentially as law enforcement agencies move towards a paperless environment. Live-scan systems, digital cameras, peripheral scanning devices and database technologies allow police to collect and archive fingerprint data directly and indirectly from a limitless number of bodies. Where police in the early twentieth century primarily amassed fingerprint records directly from criminal bodies, contemporary law enforcement agencies collect fingerprint records from criminal, non-criminal and unidentified bodies alike. The result is an increasingly inclusive identification archive and expanding state surveillance.

\section{Conclusion}

Despite its continued prominence in law enforcement and related state practices, fingerprinting has received relatively little critical attention. This is in stark contrast to the use of DNA analysis in law enforcement, which has been a site of continued debate since its inception. Because DNA contains a wealth of information beyond that which is necessary for individual identification, critics point to the potential for discrimination based on genetic information. ${ }^{8}$ Because fingerprints are only unique identifiers and reveal no information beyond the idiosyncrasies of a print's ridge characteristics, they are seen as a relatively banal form of identification. While I agree that the technique of fingerprint identification may not be cause for

\footnotetext{
8 There is a wealth of material that addresses the broad legal and social implications of DNA analysis. Two particularly good collections are Billings 1992 and Rothstein 1997. See also a special issue, "Contested Identities” of the journal Social Studies of Science (Lynch 1998).
} 
concern, I stress that the collection of fingerprints deserves continued critical attention. Livescan fingerprint readers, digital cameras and peripheral scanning devices allow police to amass fingerprint records towards an increasingly inclusive identification archive. By the year 2000, the FBI had collected 35,000,000 fingerprint records with over 630,000,000 individual fingerprint images in its Integrated Automated Fingerprint Identification System (Dussault 2000). As already noted, the recently implemented US-VISIT program will add millions of records to this archive annually. Just as fingerprinting enabled the state to bring more bodies under surveillance in the early twentieth century, so too do new media technologies bring more bodies under state surveillance through their representation in identification archives.

At stake in the continued collection and archiving of fingerprints is not simply the quantity of records. Rather, the aggregate collection of fingerprints by police, border security, immigration and other state initiatives reflect a restructuring of law enforcement and state surveillance. Law enforcement practices based on the collection of aggregates of unidentified data not only negate or reverse the presumption of innocence (Lyon 1994: 50-51), but they presuppose criminality, deviance and threat as something that is latent in all bodies. This in turn justifies and reinforces increasingly broad and expansive surveillance practices as the focus of the state shifts from the individual body to aggregate populations.

In their analysis of DNA profiling, Williams and Johnson (2004) rightly note that the effectiveness of any retroactive system of surveillance, of which both fingerprinting and DNA analysis are examples, is directly dependant on the number of records against which found data can be searched. In theory, a completely inclusive identification archive in which all members of the population are represented, would ensure that no crime went unsolved and no criminal unidentified. The authors argue that the success of DNA analysis in the U.K. is partly due to the development of an inclusive national DNA database of criminals. Inclusivity is equally important in fingerprint identification; however, where Williams and Johnson discuss the development of an inclusive DNA database of criminal bodies, I argue that fingerprint archives increasingly represent all bodies, not just criminal bodies.

Of central concern surrounding the expansion of fingerprint archives is that, as data, fingerprints can be deployed according to mutable conceptions of what constitutes criminality and deviance. Fingerprints function across a disparate array of fields and practices including employment and insurance background checks, travel documents, law enforcement, personal security, and immigration. While the fingerprint itself can only attest to presence, as part of a larger record its deployment can have both direct and lasting impacts on the identity, freedoms and capabilities of its maker. I may be denied access to a colleague's laptop through a fingerprint scanner that identifies my fingerprint as 'other than the owner' or I may be identified as a participant in a criminal act or group through a search of the FBI's Integrated Automated Fingerprint Identification System. In each case the data is the same - the ridge characteristics of my fingerprint - however, my identity, together with the rights and limitations it affords changes depending on the deployment of the data.

To further exemplify and to conclude I turn to the collection and deployment of fingerprint records in the United States under the rubric of a "war on terrorism." The National Security 
Entry-Exit Registration System (NSEERS) developed in response to the events of September 11, 2001 and was conceived as a program to enhance national security through the documentation of persons entering and leaving the country. The program was announced in June 2002 and was a precursor to US-VISIT. Like US-VISIT, NSEERS collects digital images of the fingerprints and faces of persons subject to registration. However, where US-VISIT collects fingerprint and other identification data from nearly all non-U.S. citizens, the collection of data in NSEERS was focused on Middle Eastern men. Males, sixteen years of age or older, who originated from Iran, Iraq, Libya, Sudan, Syria, Afghanistan, Algeria, Bahrain, Eritrea, Lebanon, Morocco, North Korea, Oman, Qatar, Somalia, Tunisia, United Arab Emirates, Yemen, Pakistan, Saudi Arabia, Bangladesh, Egypt, Indonesia, Jordan and Kuwait were subject to registration in NSEERS.

As part of the 'new surveillance' the collection and use of fingerprint data in programs such as NSEERS and US-VISIT depend on and are deployed according to broad categories, contexts and classifications (Marx 2002; Lyon 2003). As I have argued elsewhere (Finn 2005), the collection of identification data in NSEERS reflects and reinforces categories of suspicion based on race, gender and religious belief. That is, because the nineteen individuals involved in the September 11, 2001 hijackings were adult males from Middle Eastern nations, then all adult males from all Middle Eastern nations were categorically suspicious and subject to heightened surveillance. The purpose and rationale of such highly selective data-collection practices must be called into question. Does the collection of fingerprint records from all Middle Eastern men in NSEERS fulfil a clear need of law enforcement? Does the collection of data in this program enhance national security? And, most importantly, what is at stake in practices of data collection that are clearly discriminatory?

Changing conceptions of criminality, deviance and threat that inform the collection of data also inform its deployment and interpretation, a process that poses numerous challenges to those subject to the identification process. Take for example a Pakistani man working and residing in the United States on a valid temporary visa. During the year 2000 a database search of this man's fingerprint would reveal basic biographical information and visa status. During the year 2005, and after the implementation of NSEERS, the same fingerprint search would locate this man in a category of suspicion, marking him as a potential threat and as warranting continued surveillance. Nothing about this man has changed, yet his abilities, freedoms and liberties are dramatically reduced.

While NSEERS may seem a unique or extreme example, the collection of fingerprint data in US VISIT is cause for similar concern. The more democratic collection of fingerprints in US-VISIT is less overtly problematic than that in NSEERS. Nonetheless, fingerprints collected in both programs are acted on according to mutable categories of suspicion, threat and criminality. Fingerprints collected in US-VISIT and NSEERS are searched against various criminal history and related state databases, including an expanding archive of fingerprints collected by United States military deployed in the Middle East. Prints collected in this effort are supposedly taken from 'known terrorist locations,' however, what constitutes such a location is unclear. This is particularly alarming as an individual's mere presence in the Middle East can be taken to indicate threat or potential criminality. The large-scale collection of fingerprint records, whether selective 
or more inclusive, and the deployment of collected data must be seen as sites deserving of continued critical attention.

In combination with heightened police powers in the wake of the events of September 11, 2001, increased technological capabilities contribute to an increasingly inclusive archive of identification information. This not only yields tremendous state power, but also poses clear threats to the rights and freedoms associated with individual identity. Once photographed and archived the fingerprint becomes an immutable reference to an individual body. Once collected, our "natural inference of presence" can be acted on and identified according to mutable conceptions of what constitutes criminality and deviance.

I am not suggesting that fingerprint identification is inherently problematic or discriminatory or that a completely inclusive fingerprint database is an inescapable reality of life in the twenty-first century. However, law enforcement and state practices based on the aggregate collection of fingerprint and other identification data should be addressed and treated with informed skepticism' (Monmonier 2002: 2). The enhanced technological capabilities of law enforcement and state agencies and the unchecked, exponential expansion of fingerprint archives demand a reinvestigation of the rationale and ethical issues associated with the collection, storage and use of fingerprint data. New media technologies do not simply increase the communications and records-keeping capabilities of police. Rather, they announce a restructuring of law enforcement and surveillance practices. In the nineteenth-century rogue's gallery, the camera captured the criminal, representing his identity within the photographic frame. In the twenty-first century the image captures the body independent of any such fixed identity. The continued photographing of fingerprints in contemporary law enforcement and related state practices positions the body as a site of constant surveillance and as something that is always potentially criminal.

\section{References}

Allison, H.C. (1973) Personal Identification. Boston: Holbrook Press.

Beavan, C. (2001) Fingerprints: The Origins of Crime Detection and the Murder Case that Launched Forensic Science. New York: Hyperion.

Bertillon, A. (1890) La Photographie Judiciaire avec un Appendice sur la Classification et L'identification Anthropométriques. Paris: Gauthier-Villars.

Bertillon, A. (1893) Identification Anthropométrique: Instructions Signalétiques - Album. Melun: Imprimerie Administrative.

Bertillon, A . (1975) Bertillon's Instructions for taking descriptions for the identification of criminals, and others by the means of anthropometric indications. New York: AMS Press.

Billings, P.R. (ed.) (1992) DNA on Trial: Genetic Identification and Criminal Justice. Plainview: Cold Springs Harbor Laboratory.

Brotman, B.J. and R.K. Pavel (1991) 'Identification: A Move Toward the Future,' Law Enforceme nt Bulletin July. 
Carey, T., Assistant Special Agent in Charge, Washington Field Office, FBI. (2001) 'Communication with the Law Enforcement Community,' Congressional Statement, November 13, 2001. http://www.fbi.gov/congress/congress01/carey111301.htm [Accessed September 2002]

Cherrill, F.R. (1954) The Finger Print System at Scotland Yard. London: HMSO.

Cole, S. (1998) 'Manufacturing Identity: A History of Criminal Identification Techniques From Photography Through Fingerprinting,' Unpublished PhD Dissertation, Cornell University.

Cole, S. (1998b) 'Witnessing Identification: Latent Fingerprinting Evidence and Expert Knowledge,' Social Studies of Science 28 (5-6): 687-712.

Cole, S. (2001) Suspect Identities: A History of Criminal Identification and Fingerprinting. Cambridge: Harvard University Press.

Cooper, H.S. (1981) 'The Evolution of Canadian Police,' in W.T. McGrath and M.P. Mitchell (eds.) The Police Function in Canada. Toronto: Methuen, 37-52.

Coopersmith, J. (1993) 'Facsimile's False Starts,' IEEE Spectrum, February: 46-49.

Costigan, D.M. (1978) Electronic Delivery of Documents and Graphics. New York: Van Nostrand Reinhold Company.

Daston, L and P.Galison (1992) 'The Ima ge of Objectivity,' Representations 40: 81-128.

Dilworth, D.C. (ed.) (1976) The Blue and the Brass, American Policing: 1890-1910. Police History Series. Gaithersburg: International Association of Chiefs of Police.

Dilworth, D.C. (ed.) (1977) Identification Wanted: Development of the American Criminal Identification System 1893 - 1943. Police History Series. Gaithersburg: International Association of Chiefs of Police.

Duncan, Chief Inspector J.H. (1942) An Introduction to Fingerprints. London: Butterworth and Company.

Dussault, R. (2000) 'Cause and Effect,' Government Technology April. http://www.govtech.net/publications/crimetech/Apr00/CTEfingerprints.phtml [Accessed January 9 2003]

Faulds, H. (1880) 'On the Skin-Furrows of the Hand,' Nature 22 (October 28): 605.

Federal Bureau of Investigation (1999) Inauguration of the Integrated Automated Fingerprint Identification System (IAFIS),' Press Release, August 10. http://www.fbi.gov/pressrel/pressrel99/iafis.htm [Accessed November 2002]

Finn, J. (2003) 'Police Photography: Visual Representation, Scientific Evidence and the Construction of the Criminal,' Unpublished PhD. Dissertation, University of Rochester.

Finn, J. (2005) 'Potential Threats and Potential Criminals: Data Collection in the National Security Entry-Exit Registration System,' in M. Salter and E. Zureik (eds.) Global Surveillance: Borders, Security, Identity. Devon: Willan.

Foucault, M. (1979) Discipline and Punish: the Birth of the Prison. trans. Alan Sheridan. New York: Vintage Books.

Galison, p. (1998) 'Judgment Against Objectivity,' in C.A. Jones and P. Galison (eds.) Picturing Science Producing Art. New York: Routledge, 327-359. 
Galton, F. (1888a.) 'Personal Identification and Description: 1,' Nature 38 (June 21): 173-77.

Galton, F (1888b) ‘Personal Identification and Description: 2,' Nature 38 (June 28): 201-202.

Galton, F. (1892) Finger Prints. London: Macmillan.

Green, D. (1984) ‘Classified Subjects,' Ten.8 14: 30-37.

Green, D. (1985a) ‘On Foucault: Disciplinary Power and Photography,' Camerawork 32: 6-9.

Green, D. (1985b) 'Veins of Resemblance: Photography and Eugenics,' The Oxford Art Journal 7(2): 3-16.

Gunning, T. (1995) 'Tracing the Individual Body: Photography, Detectives, and Early Cinema,' in L. Charney and V.R. Schwartz (eds.) Cinema and the Invention of Modern Life. Berkeley: University of California, 15-45.

Henry, Sir E.R. (1900) Classification and Uses of Finger Prints, 7th [1934] ed. London: HMSO.

Herschel, W. J. (1880) 'Skin Furrows of the Hand,' Nature 23 (November 25): 76.

Lalvani, S. (1996) Photography, Vision, and the Production of Modern Bodies. Albany: State University of New York.

Lescarboura, A.C. (1920) ‘Sending Photographs Over Wires,' Scientific American 123: 474-84.

Lynch, M.and S.Jasanoff (1998) ‘Contested Identities: Science, Law and Forensic Practice,' Special Issue, Social Studies of Science, 28 (5-6).

Lyon, D. (1994) The Electronic Eye: The Rise of Surveillance Society. Minneapolis: University of Minnesota Press.

Lyon, D. (2003) ‘Surveillance as Social Sorting: Computer Codes and Mobile Bodies,' in D. Lyon (ed.) Surveillance as Social Sorting: Privacy, Risk and Digital Discrimination. New York: Routledge, 13-30.

Marx, G. (2002) 'What's New About the "New Surveillance"? Classifying for Change and Continuity,' Surveillance and Society, 1 (1): 9-29. http://www.surveillance-and-society/articles1/whatsnew.pdf

McCahill, M. (1998) 'Beyond Foucault: Towards a Contemporary Theory of Surveillance,' in C.Norris, J. Moran and G. Armstrong (eds.) Surveillance, Closed Circuit Television and Social Control . Aldershot: Ashgate, 41-65.

Monmonier, M.(2002) Spying with Maps: Surveillance Technologies and the Future of Privacy. Chicago: University of Chicago Press.

Norris, C. (2003) 'From Personal to Digital: CCTV, the Panopticon and the Technological Mediation of Suspicion and Social Control,' in D. Lyon (ed.) Surveillance as Social Sorting: Privacy, Risk and Digital Discrimination. New York: Routledge, 249-281.

Phillips, Sandra, Mark Haworth-Booth, and Carol Squires. 1997. Police Pictures: The Photograph as Evidence. San Francisco: Chronicle Books.

Reed, B. (1981) 'Automated Fingerprint Identification: From Will West to Minnesota Nine-Fingers and Beyond,' Journal of Police Science and Administration 9 (3): 317-326.

Rejlander, O.G. (1872) 'Hints Concerning the Photographing of Criminals,' The British Journal Photographic Almanac 116-117. 
Finn: Photographing Fingerprints

Rhodes, H.T.F. (1956) Alphonse Bertillon, Father of Scientific Detection. London: Harrap.

Rothstein, M.A. (ed.) (1997) Genetic Secrets: Protecting Privacy and Confidentiality in the Genetic Era. New Haven: Yale University Press.

Sekula, A. (1986) 'The Body and the Archive,' October 39: 3-64.

Tagg, J. (1988) The Burden of Representation: Essays on Photographies and Histories. Basingstoke: Macmillan.

Tuttle, H.B. (1961) 'History of Photography in Law Enforcement,' Finger Print and Identification Magazine 43(4): 3-28.

Wentworth, B. and H.H. Wilder (1932) Personal Identification: Methods for the Identification of Individuals, Living or Dead. Chicago: T.G. Cooke.

Williams, R. and P. Johnson (2004) ‘Circuits of Surveillance,' Surveillance and Society 2 (1): 1-14. http://www.surveillance-and-society/articles2(1)/circuits.pdf

Wilson, T.F. (1986) 'Automated Fingerprint Identification Systems,' Law Enforcement Technology August / September: 17-46.

Wilton, G.W. (1938) Fingerprints: History, Law and Romance. London: William Hodge and Company.

Woodbury, W.B. (1875) 'Photographing Criminals,' The British Journal Photographic Almanac 128. 